\title{
The Effect of Spiritual Intelligence Training on Human Dignity in Patients with Cancer: Clinical Trial
}

\author{
Bibi Maryam Hashemi', Saeed Sarabian², Masoud Kashani Lotfabadi ${ }^{3}$,Sare Hosseini ${ }^{4,}$ Azam \\ Mohammadi $^{5}$
}

1. Ms in Islamic Psychology, Payam Noor University of Gonabad, Gonabad, Iran

2. Assistant Professor of Child and Adolescent Clinical Psychology, Payame Noor University of Mashhad, Mashhad, Iran

3. Ms in Psychiiatry clinical, Psychiatry and Behavioral Sciences Research Center, Ibn-Sina psychiatric hospital, Mashhad University of Medical Sciences, Mashhad, Iran

4. Assistant Professor of Radiotherapy and Oncology, Cancer Research Center, Faculty of Medicine, Mashhad University of Medical Sciences, Mashhad, Iran

5. Ms in Nursing Psychiatric, Psychiatry and Behavioral Sciences Research Center, Ibn-Sina psychiatric hospital, Mashhad University of Medical Sciences, Mashhad, Iran

\section{Article Info \\ Received: 2018/12/30; \\ Accepted: 2019/01/8; \\ Published Online: 2019/03/27 \\ $\underline{10.30699 / \mathrm{sjhnmf} .27 .4 .209}$}

Original Article

Use your device to scan and read the article online

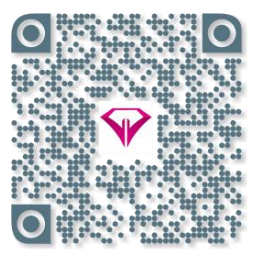

\section{ABSTRACT}

Introduction: Diagnosis of cancer is associated with fear of dying, which greatly affects the human dignity of the individual. In Iran, the psychological issue of these patients, including human dignity and interventions in this field, has been underestimated. The aim of this study was to determine the effect of spiritual intelligence training on human dignity in cancer patients.

Methods: This randomized clinical trial with control group was performed on 50 cancer patients admitted to Omid Hospital in Mashhad in 2018 - 2019 (May -Jun). The patients were selected by available method and randomly assigned to two groups of intervention (23 patients) and control $(n=27)$. The intervention group underwent spiritual intelligence training according to King's (2008) model during ten sessions of one and a half hours. The control group received routine care. The data collection tool was a standard patient dignity inventory that was completed in two steps before intervention and 8 weeks after intervention. Data was analyzed using SPSS 21 software, t-paired and t-independent test.

Results: Both groups were homogeneous for demographic variables and there was no statistically significant difference between the two groups. There was no significant difference between the scores of both groups before entering the study ( $P$ $=0.68$ ). There was a significant difference between the mean scores of the two groups before intervention and 8 weeks after intervention $(P<0.001)$.

Conclusion: Spiritual intelligence training can enhance human dignity in cancer patients. Therefore, it is recommended to use it in hospitals.

Keywords: Spiritual intelligence, Education, Cancer, Human dignity

\section{How to Cite This Article:}

Hashemi B M, Sarabian S, Kashani Lotfabadi M, Hosseini S. The Effect of Spiritual Intelligence Training on Human Dignity in Patients with Cancer: Clinical Trial. Avicenna J Nurs Midwifery care. $2019 ; 27$ (4) 
• ا T تأثير آموزش هوش معنوى بر شأن انسانى مبتلايان به سرطان 
بررسى تأثير آموزش هوش معنوى بر شأن انسانى در بيماران مبتلابه سرطان: كار آزمايى بالينى

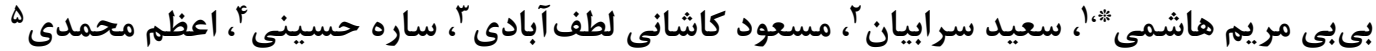

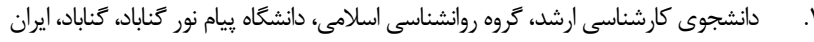

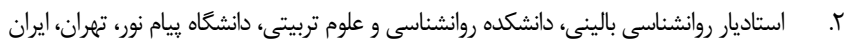

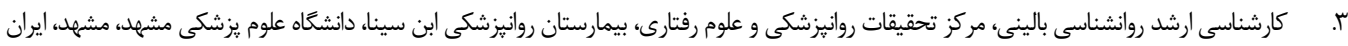

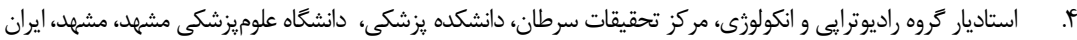

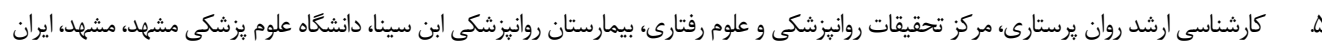

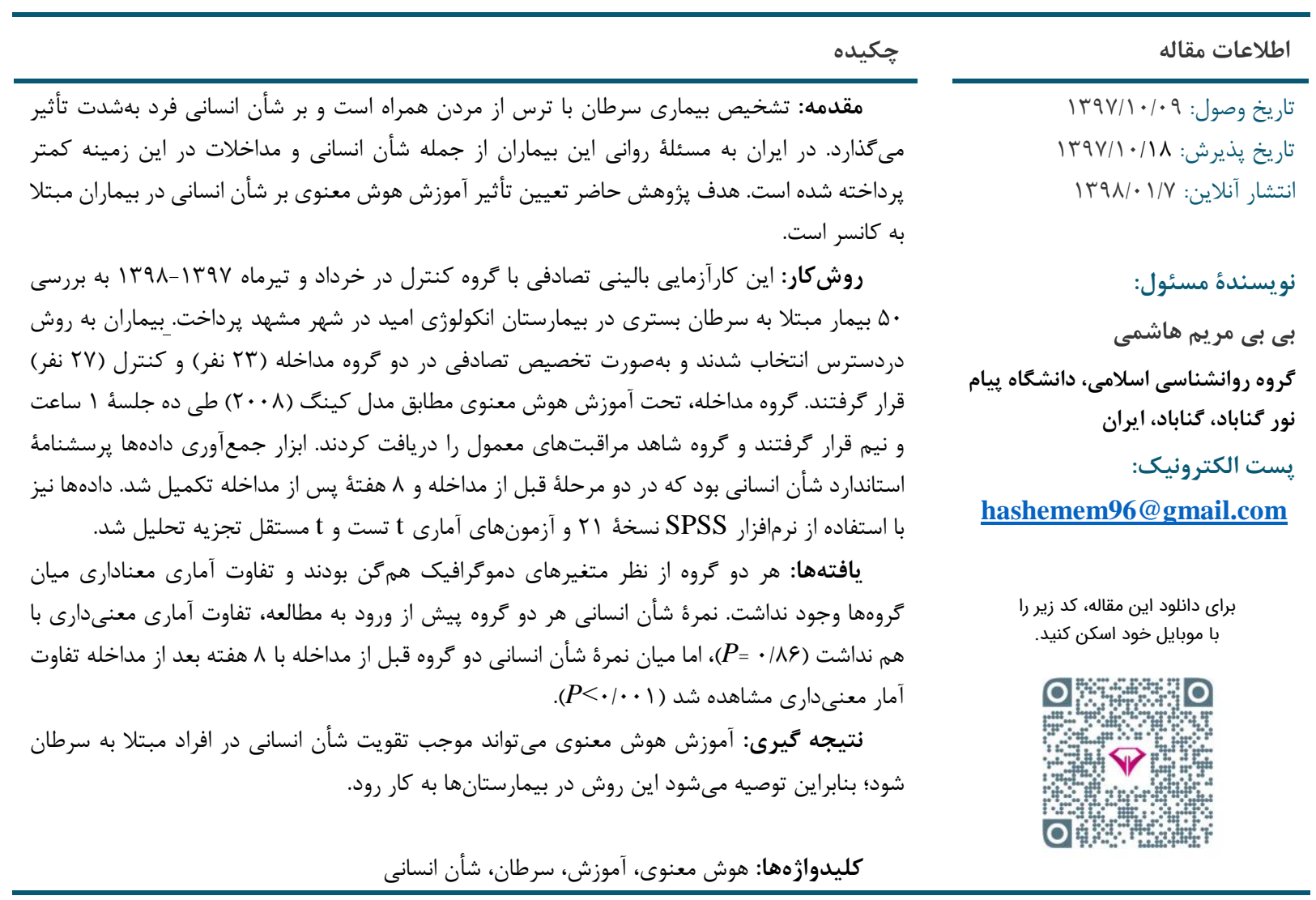

مقدمه

بهداشتى تبديل كرده []

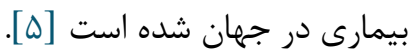

سرطان كه يكى از تلخترين تجربيات بشرى است، بر استر

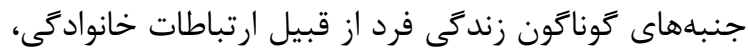

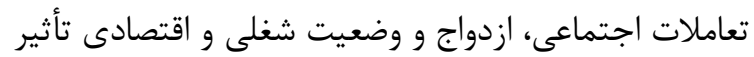

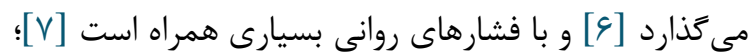
بلاطورى كه اين بيماران علاوه بر مشكلات جسمانى ناشى از از

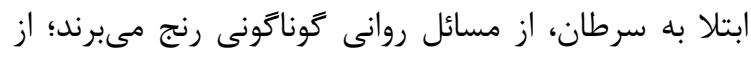

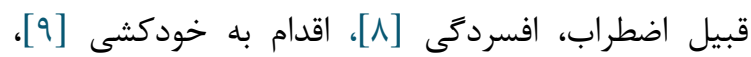
رضايتنداشتن از تصوير بدنى (بهدليل تغييرات ظاهرى و
سرطان سومين علت شايع مرك (يس از بيمارىهاى

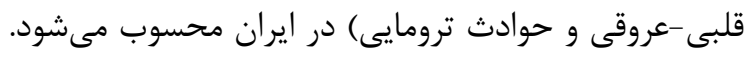

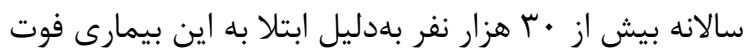

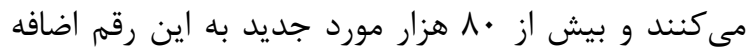

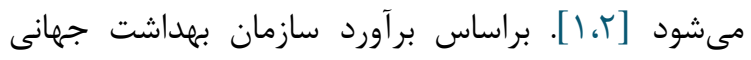

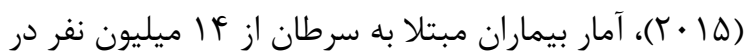

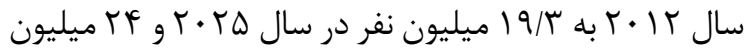

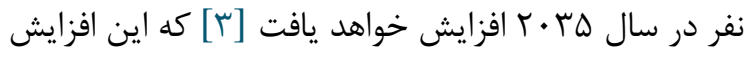
روزافزون بيمارى سرطان را به يكى از خالشهای خرای نظام 
rاT تأثير آموزش هوش معنوى بر شأن انسانى مبتلايان به سرطان

[Tr]] بلهطورى كه در ايران نيز شأن انسانى بيمار در دو زمينهُ اصلى پايه (احساس امنيت، دريافت مراقبت جامع، ارتباطات

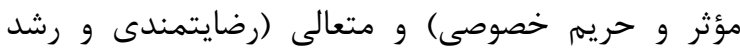
معنوى) ادغام و تعريف شده است [ب آ] براساس نتايج مطالعات متعدد، كاربرد منابع معنويت و و

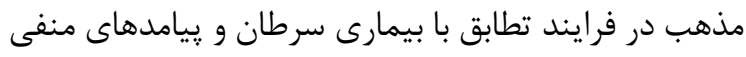

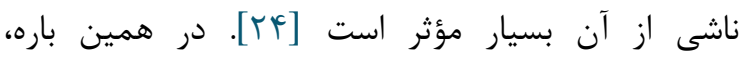
Pargament

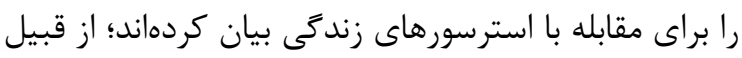

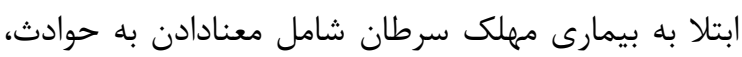

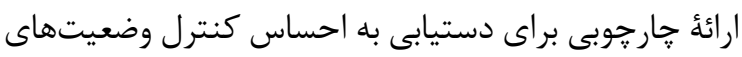
دشوار، فراهمكردن راحتى در زمان سختى، برقرارى ارتئ ارتباط

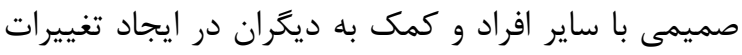

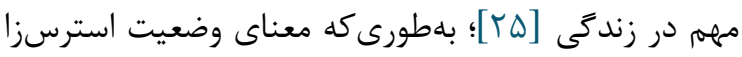

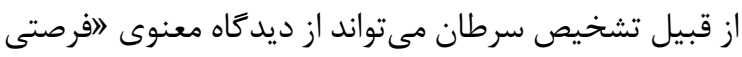
براى رشده (بازنكرى مذهبى خيرخواهانه) و از ديدكاه

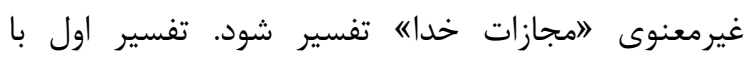

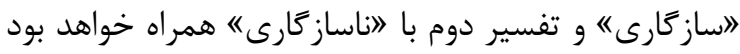

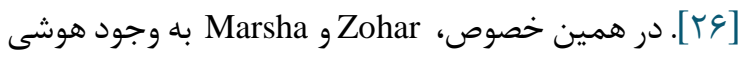

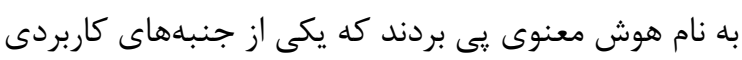

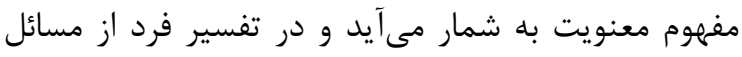

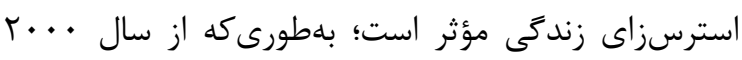

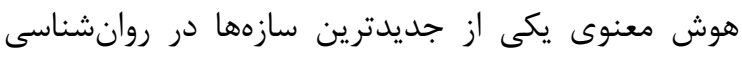

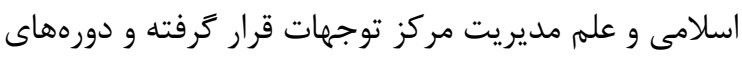

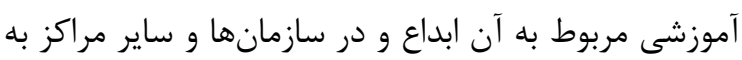

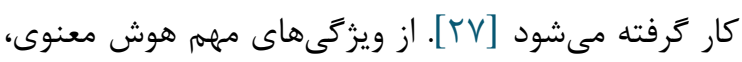

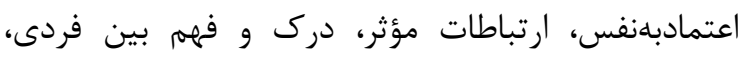
تغييرات معنادار زندگى و حركت از مسير مشكلات است كه

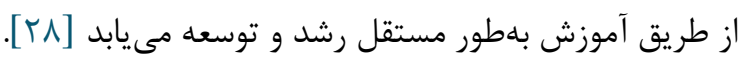

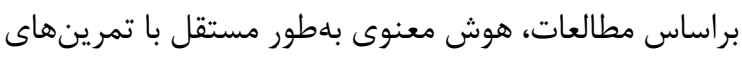

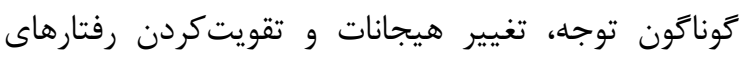

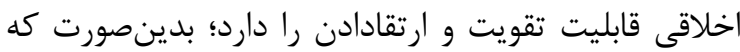

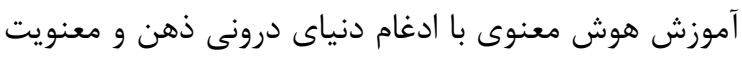

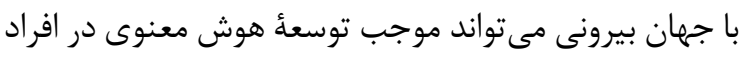

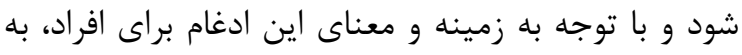

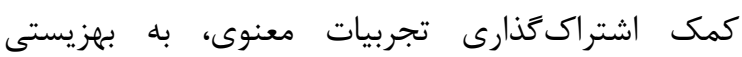
روانشناختى و سلامت عمومى افراد كمك كند؛ زيرا معنويت در قلب و ذهن هر انسانى وجود دارد و مستقل از آداب و وداديق
بيمارى طولانىمدت)، كيفيت زندگى پايين، احساسى مبنى

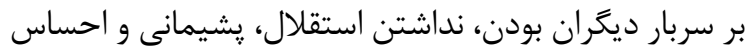

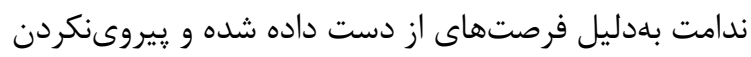
از اصول معنايى زندگى مطابق ارزشها و عقايد [11]؛ درحالى كه احساس درماندگى، دلسردى و ندامت در افراد

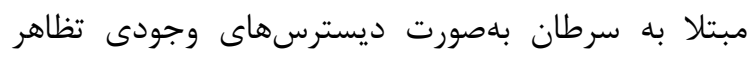

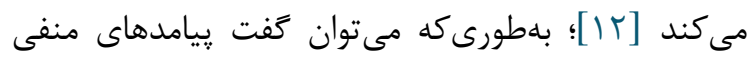
سرطان علاوه بر ترس و اضطراب شامل شك و ترديد به ارزشها و عقايد مذهبى و تخريب هويت نيز است كه

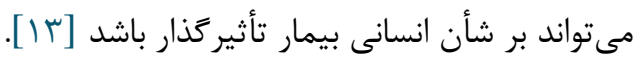

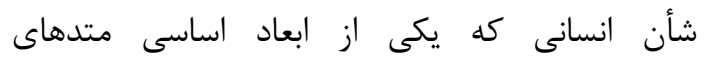

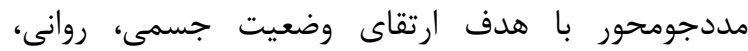

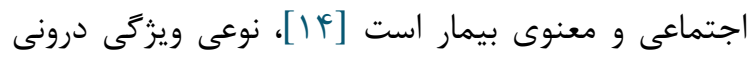

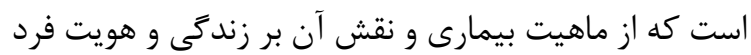

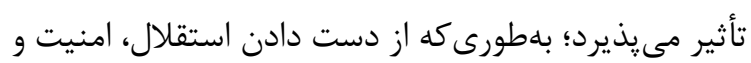

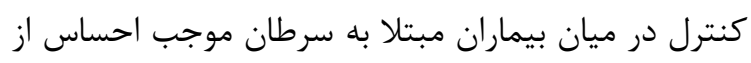

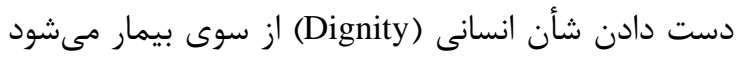

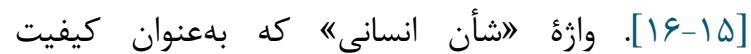

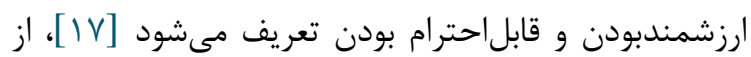

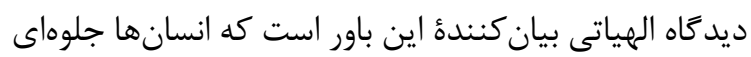

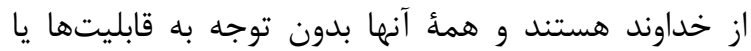

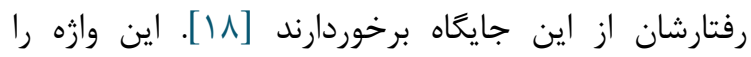

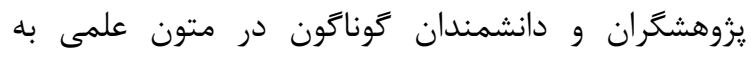

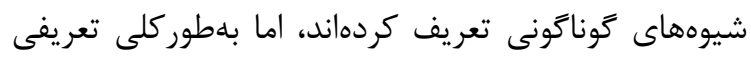

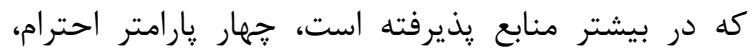

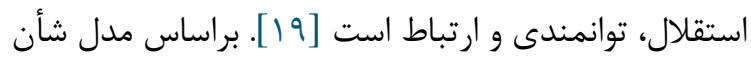

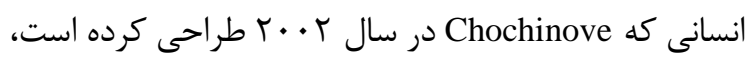

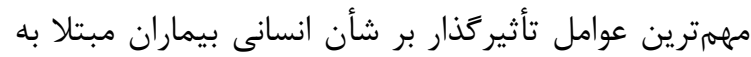
سرطان، نكرانىهاى مربوط به بيمارى (درد، اضطراب، ترس

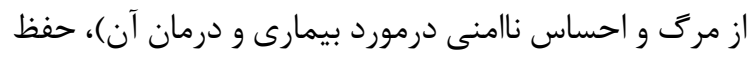

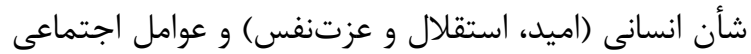
(حمايت اجتماعى و تعاملات با ديخران بهويزه خانواده و

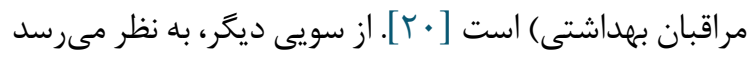

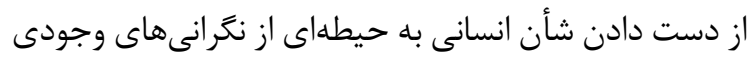

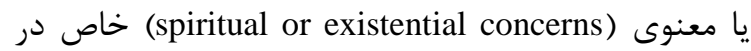

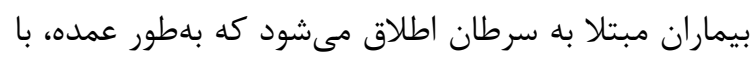
ديسترسهاى وجودى (ضد اخلاقيات) در اين بيماران همراه

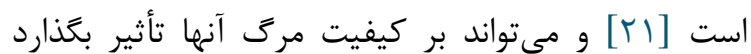


بسترى در اين بيمارستان صورت گرفت. حجم نمونه براساس

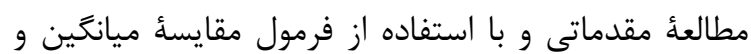
$\frac{\left(z_{1}-\alpha / 2+z_{1-\beta}\right)^{2}\left(s_{1}^{2}+s_{2}^{2}\right)}{\left(\bar{x}_{1}-\bar{x}_{2}\right)^{2}}$

از طريق محاسبة ميانگين و انحراف معيار نمره كل شأن انسانى در كروه مداخله (r/r

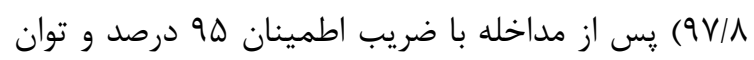

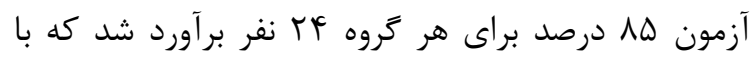

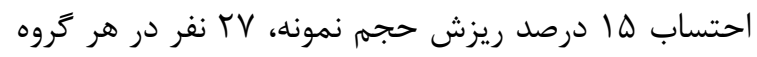

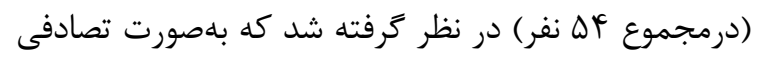

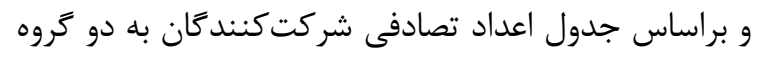

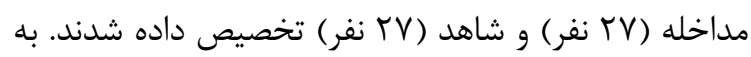

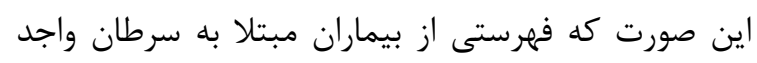

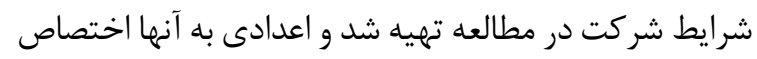

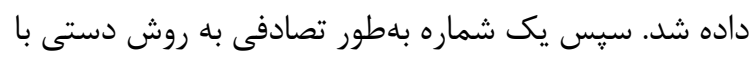

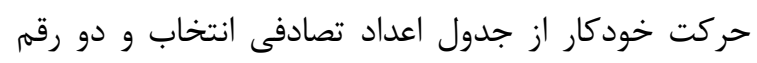

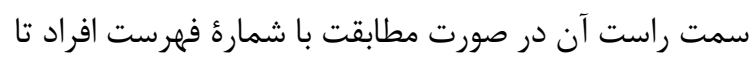

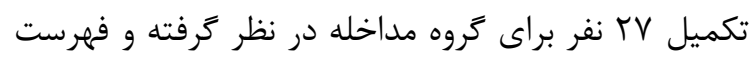

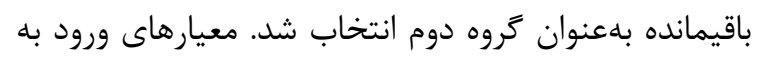

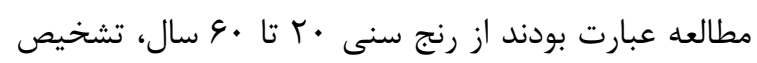
قطعى سرطان توسط انكولوزيست، حداقل سطح تحصيلات

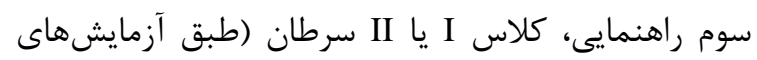

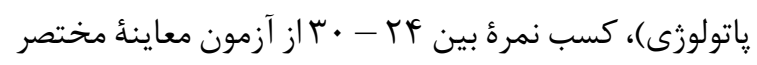
روانيزشكى (MMSE) كه روانشناس بالينى اجرا كرد.

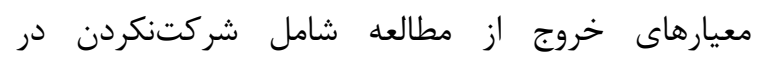

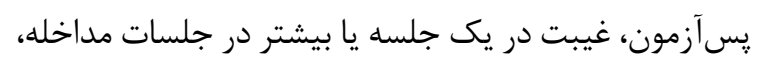
تمايلنداشتن به ادامئ شركت در مطالعه بودند

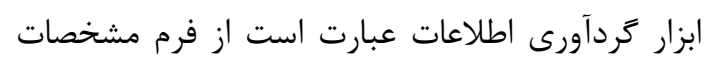

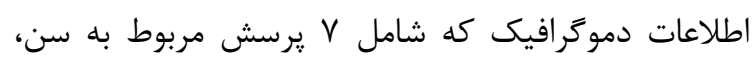

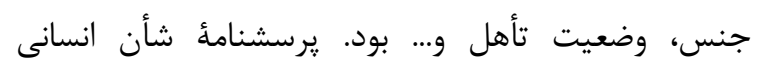

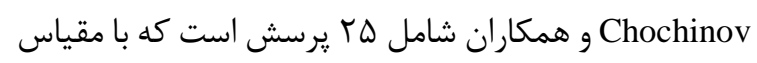

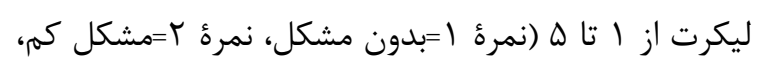

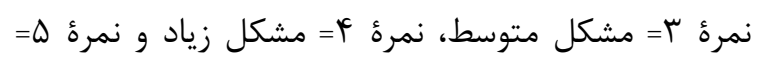

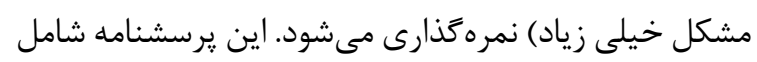

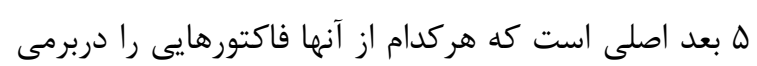

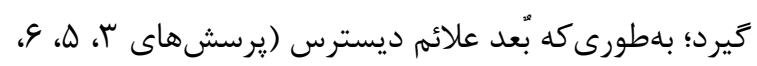

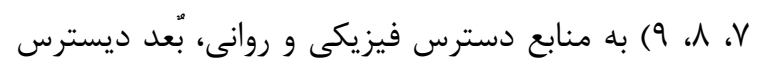

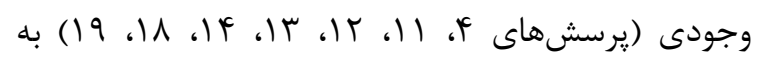

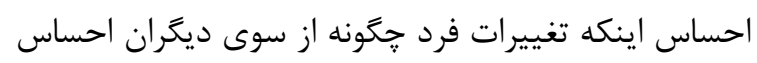

سنتهاى مذهبى افراد است [\%彳]. از آنجا كه هوش معنوى

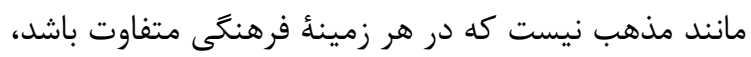

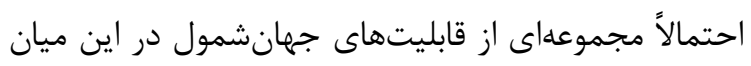

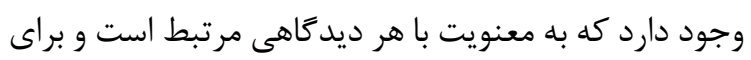

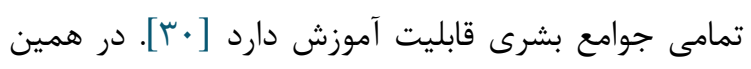

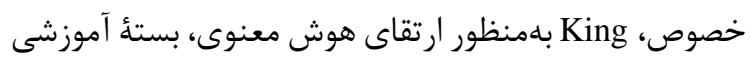

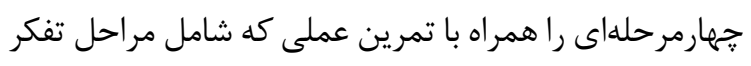

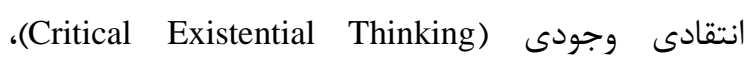

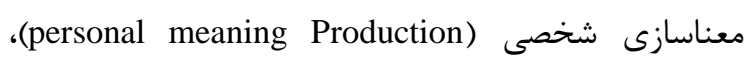

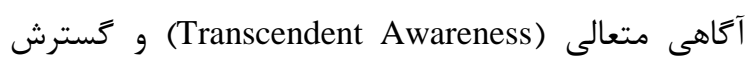

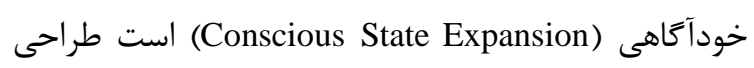

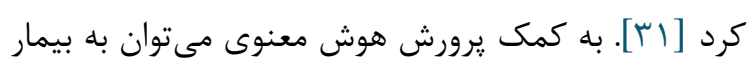

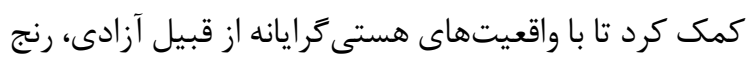

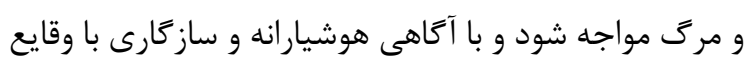

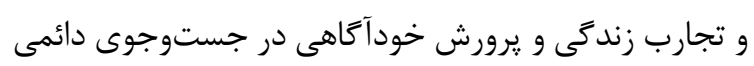

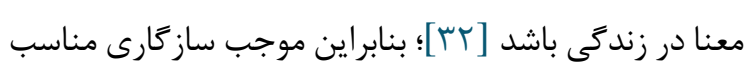

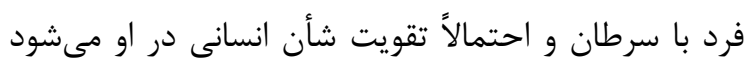

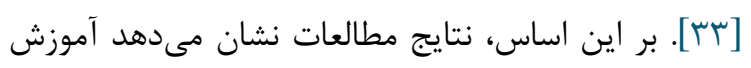

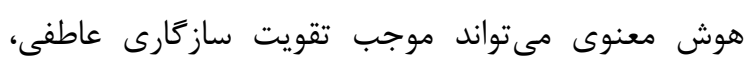

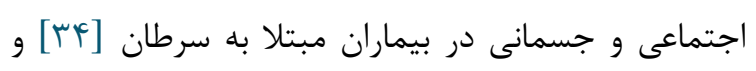

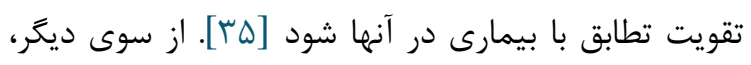

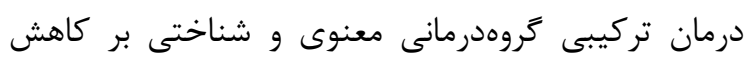

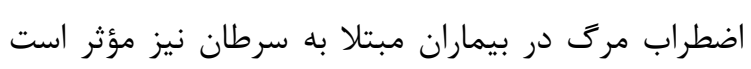

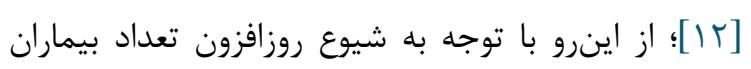

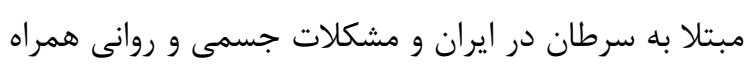

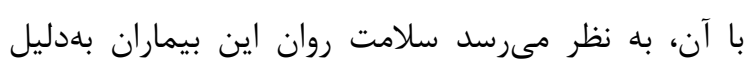

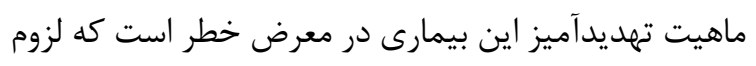

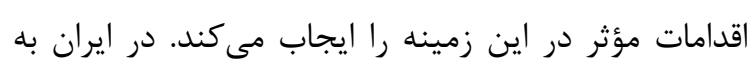

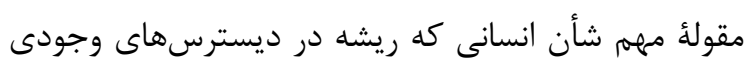

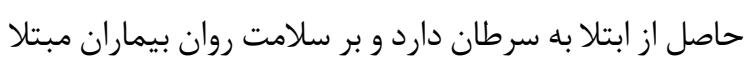

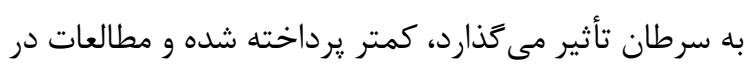

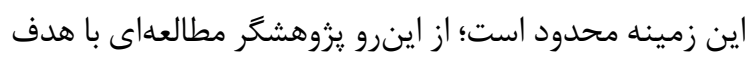

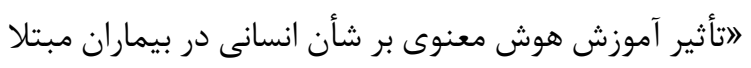

$$
\text { به سرطانه صورت داد. }
$$

اين مطالعئ حاضر كارآزمايى بالينى تصادفى با كروه

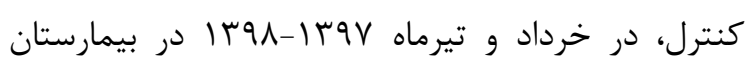

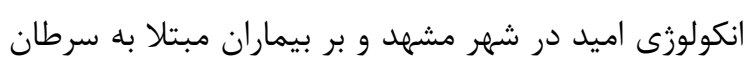


TIF تأثير آموزش هوش معنوى بر شأن انسانى مبتلايان به سرطان

و نيم دو بار در هفته (روزهاى يكشنبه و ينجشنبه) بركزار شد. عناوين جلسات بلترتيب عبارت بودند از:

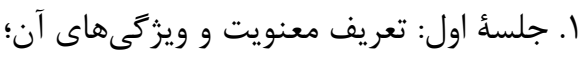

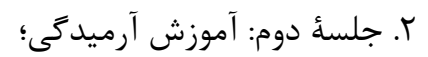

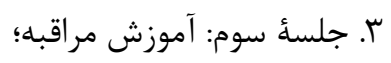

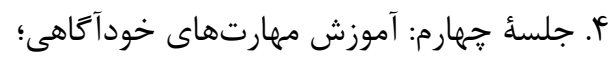

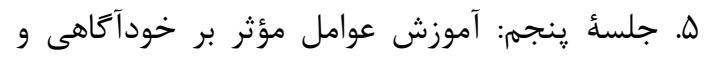

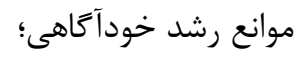

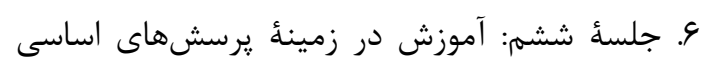
زندگى؛ V. جلسأ هفتم: آموزش راههاى يافتن معنا در زندكى و

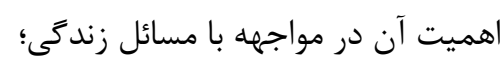

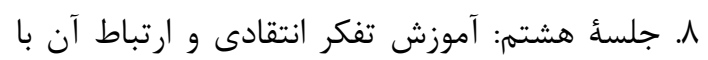

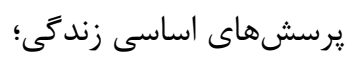

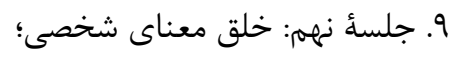

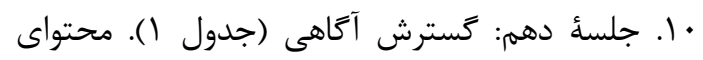

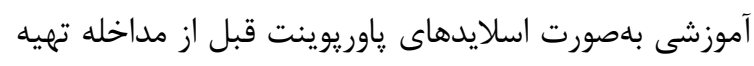

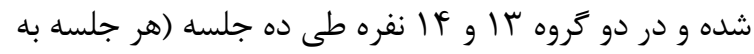

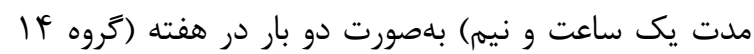

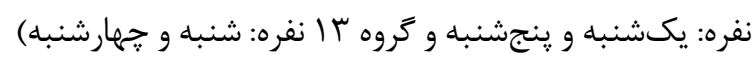

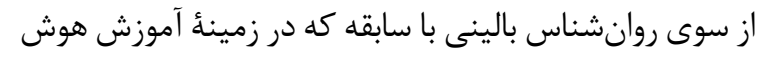

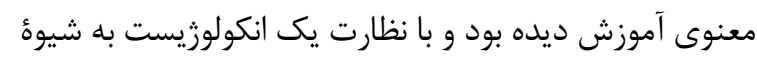

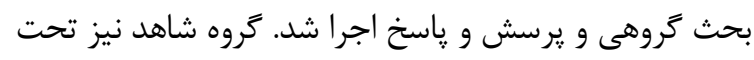
مراقبتهاى معمول بيمارستان قرار كرفت.

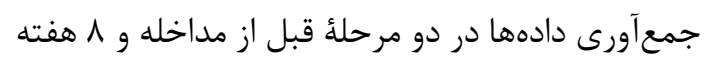

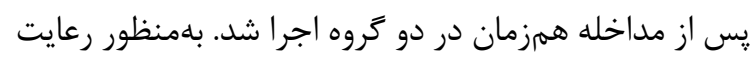

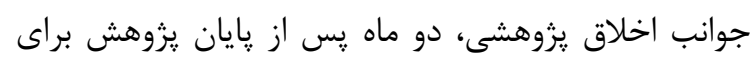

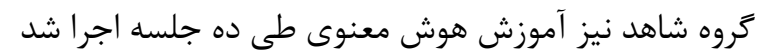

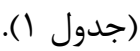

در همأ مراحل يزوهش، تمام نكات اخلاق در يزوهش

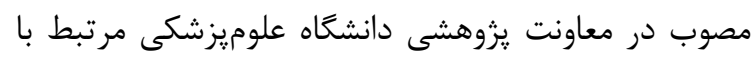

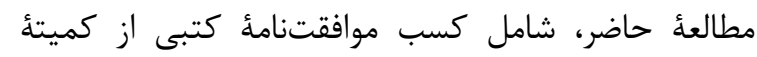

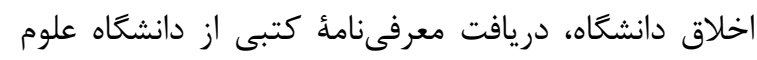

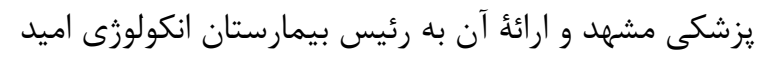

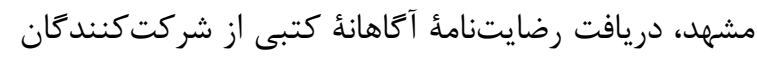

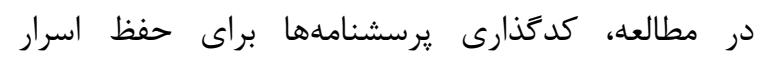

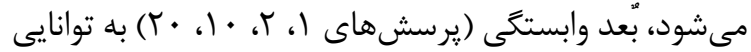

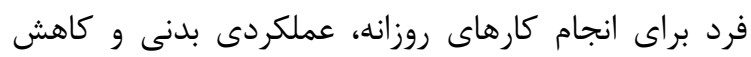

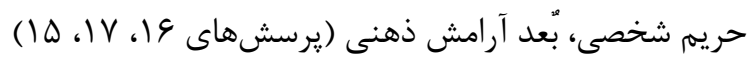

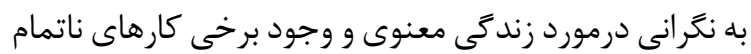

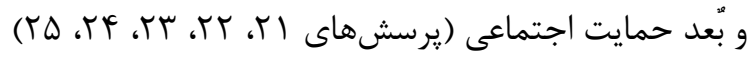

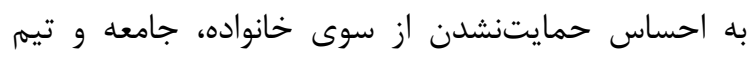

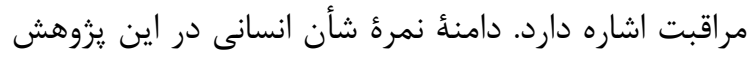

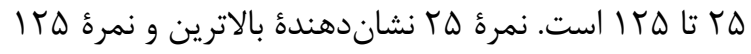

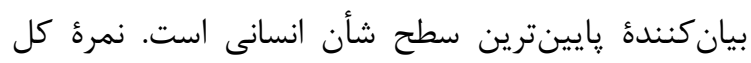

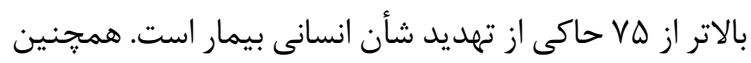

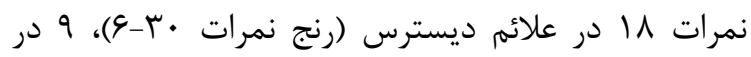
آرامش ذهنى (رنج نمرات

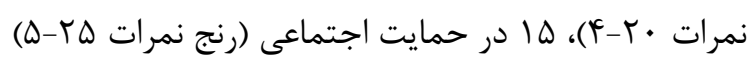

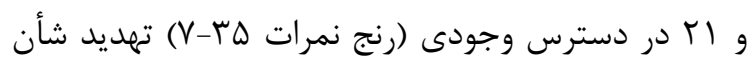

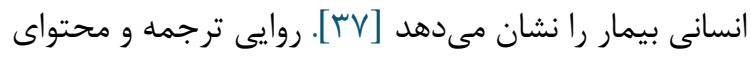
اين ابزار، در مطالعهُ Vaghee و همكاران در ايران تأييد شده

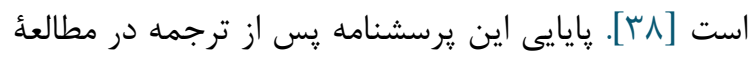

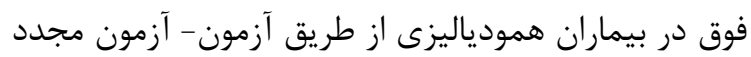

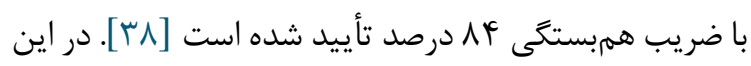

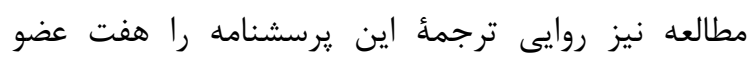

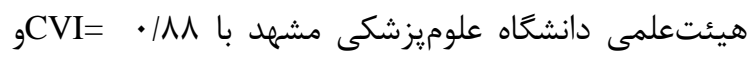

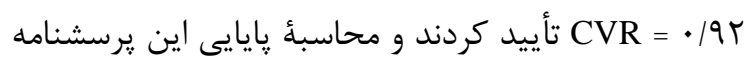
به روش همرسانى درونى با ضريب آلفاى كرونباخ الج 9 درصد

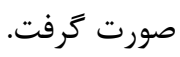
نمونهَيرى ابتدا به روش غير غيراحتمالى (نمونهَيرى

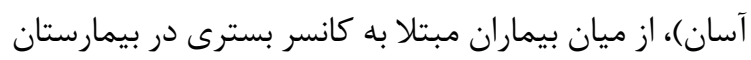

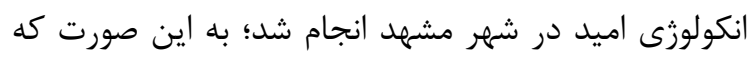

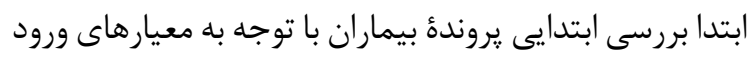

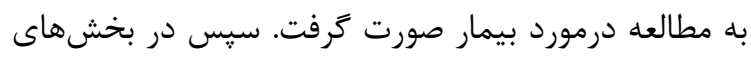

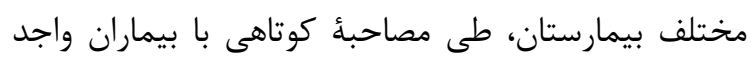

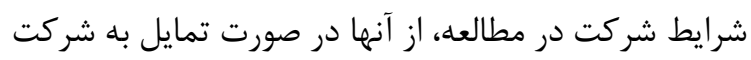

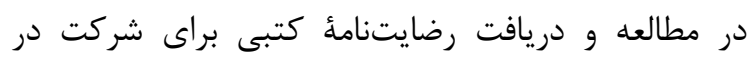

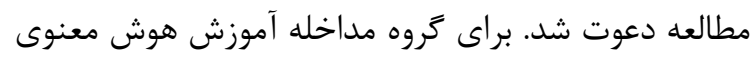

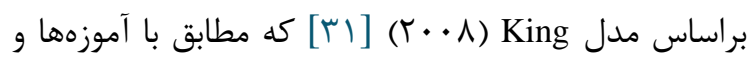

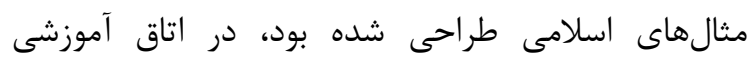

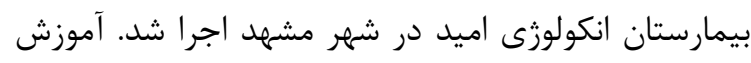

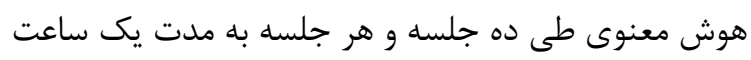


جدول ا. محتواى بستهُ آموزش هوش معنوى براساس مدل كينَ (1+•؟)

\begin{tabular}{|c|c|c|c|c|c|}
\hline 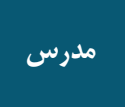 & شوز ش شيوه & زمان & محتوا & هدف & عنوان \\
\hline 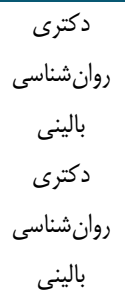 & 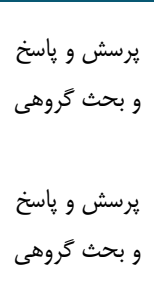 & س اعت 1/ه & 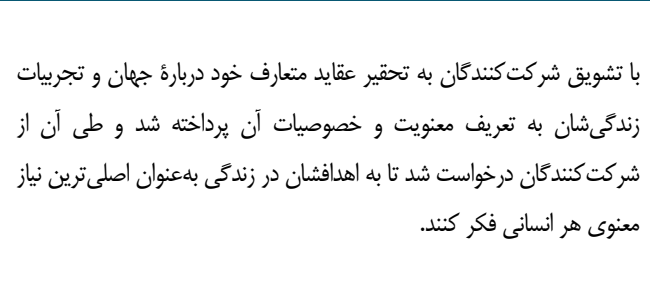 & معارفه و تعريف معنويت و ويثَى هاى آن & جلسؤ اول \\
\hline بالينى دوانشى د & و يرسش و ياسخ & 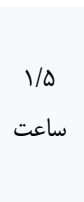 & 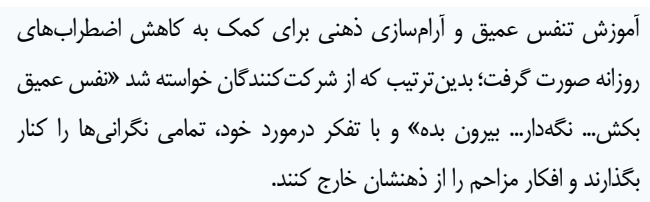 & آموزش آرميدگى & جلسة دوم \\
\hline بالينى دوان شناسى & و برسش و يَاسخ & 1/ه 1/ه & 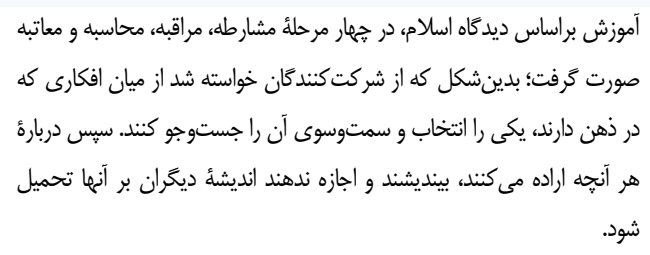 & آموزش مراقبه & جلسأ سوم \\
\hline روانشناسى دالينى & 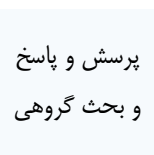 & س ساعت 1/ه & 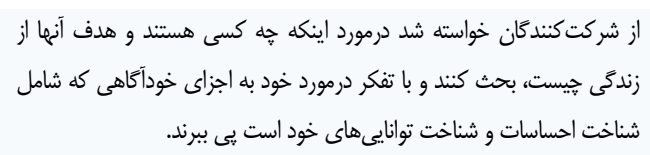 & خودآَكاهى مهارتهاى & جلسأ حهارم \\
\hline بالينى دوان شتاسى & و برسث و يَاسخ & 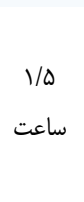 & 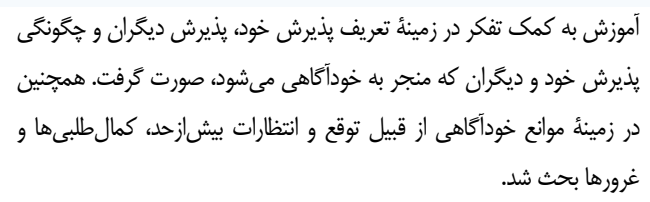 & خوآ آمَاه عوامل و موانع آنثر بر & جلسؤ ينجم \\
\hline روانشناسى دالينى & و برسث و ياسخ & س اعت 1/ه & من كيستم؟ آيا اين جهان در بى هدفى است؟ من اختيار دارم يا مجبورم؟ & آموزش در زمينُٔ يرسشهاى & جلسة ششم \\
\hline بالينى دوانشى د بناسى & و برسش و ياسخ & س اعت 1/ه & مذهبى به خه معناست و هدف از رنج جيست؟ (با مثال هايى از شخصيتهاى مهمم & 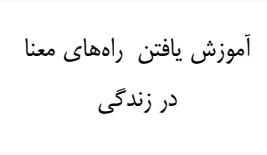 & جلسئ هفتم \\
\hline بالينى دوانشاسى & و برسش و ياسخ & س اعت 1/ه & 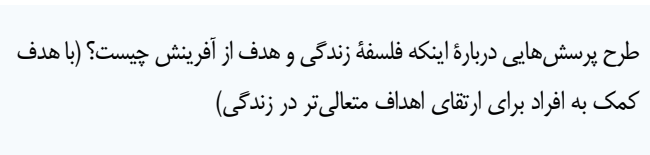 & تفكر وجودى انتقادى & جلسأ هشتم \\
\hline 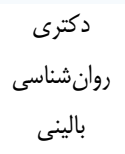 & و برسش و ياسخ & 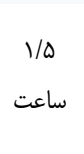 & 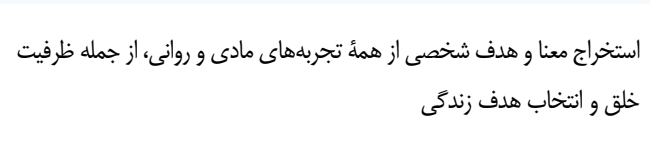 & 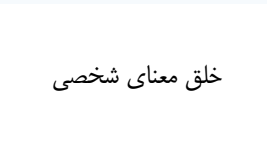 & جلسأ نهم \\
\hline روانشناسى دالينى & و برسث و پِاسخ & س اعت 1/ه & 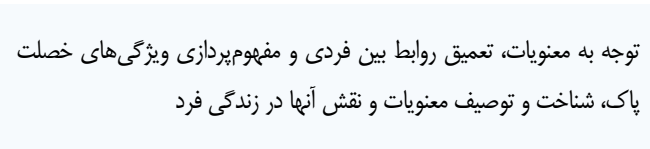 & كَسترش آكاهى & جلسأ دهم \\
\hline
\end{tabular}

براى توصيف فراوانى دادهها از آمار توصيفى و براى مقايسٔ

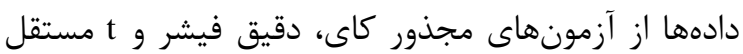

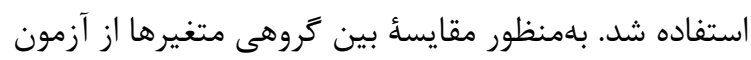

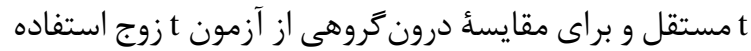

شركت كنند كان و اطمينان به آنها براى خروج از يزوهش، در هر زمان در صورت تمايلنداشتن به ادامهٔ مطالعه رعايت شد. تحليل دادهاى يزوهش در نرمافزار SPSS نسخدان

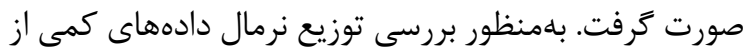

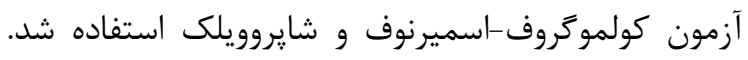


جدول r. مقايسُٔ متغير هاى دموكرافيك افراد مبتلا به سرطان به تفكيك تروه مداخله و كنترل

\begin{tabular}{|c|c|c|c|c|}
\hline \multirow{2}{*}{ نتيجهُ آزمون } & شاهد (Y نفر) & مداخله (بآ نفر) & تروه & \\
\hline & تعداد (درصد) & تعداد (درصد) & متغير & \\
\hline \multirow{2}{*}{$\begin{array}{c}\mathrm{x}^{2}=\cdot / \cdot 1 \\
\mathrm{df}=1 \\
P^{*}=\cdot / \Delta \mathrm{V}\end{array}$} & $N(\varepsilon \& / V)$ & $1 \Delta(\Phi \Delta / T)$ & مؤنث & \multirow{2}{*}{ 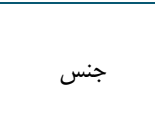 } \\
\hline & $q(\Gamma r / r)$ & $\Lambda(M F / \Lambda)$ & مذكر & \\
\hline \multirow{4}{*}{$\begin{array}{c}\mathrm{x}^{2}=\cdot / 94 \\
\mathrm{df}=r \\
P^{* *}=\cdot / 19\end{array}$} & 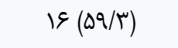 & $10(\Phi \Delta / \Gamma)$ & متأهل & \multirow{4}{*}{ وضعيت تأهل } \\
\hline & $f(I F / \Lambda)$ & $\Delta(r, / V)$ & مجرد & \\
\hline & $r(V / \mathcal{E})$ & $r(1 r)$ & مطلقه & \\
\hline & $\Delta(1 N / \Delta)$ & $(\cdot)$ & بيوه & \\
\hline \multirow{3}{*}{$\begin{array}{c}\mathrm{X}^{2}=r / \Lambda \mathrm{r} \\
\mathrm{df}=\mathrm{r} \\
P^{* *}=\cdot / \Lambda \Delta\end{array}$} & $\operatorname{IV}(\varepsilon \tilde{\mu})$ & $\operatorname{lr}(\Delta s / \Delta)$ & سوم راهنمايى & \multirow{3}{*}{ سطح تحصيلات } \\
\hline & $V(T \Delta / Q)$ & $V(r \cdot / \mathcal{F})$ & دييلم & \\
\hline & $r(11 / 1)$ & r(Ir) & تحصيلات دانشگاهى & \\
\hline \multirow{7}{*}{$\begin{array}{c}\mathrm{x}^{2}=\varepsilon / \Delta \mathrm{r} \\
\mathrm{df}=\varepsilon \\
P^{* *}=\cdot / \mathrm{VV}\end{array}$} & $9(r r / r)$ & $\Lambda(M Y / \Lambda)$ & روده & \multirow{7}{*}{ عضو مبتالا به } \\
\hline & $r(\mid r / \Lambda)$ & $1(F / \mu)$ & ع عستان & \\
\hline & $1(r / V)$ & $r(\Lambda / V)$ & تخمدان & \\
\hline & $r(V / F)$ & $\Delta(r, / V)$ & مرى & \\
\hline & $g(Y T / T)$ & $9(1 / T 9)$ & معده & \\
\hline & $r(V / F)$ & $1(\mathcal{F} / \Psi)$ & مغز استخوان & \\
\hline & $r(11 / 1)$ & $\cdot(\cdot)$ & رحم & \\
\hline \multirow{4}{*}{ 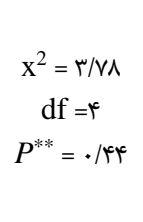 } & $1(r / V)$ & $1(\mathcal{F} / \mu)$ & استخدام دولتى & \multirow{4}{*}{ وضعيت اشتغال } \\
\hline & $\wedge(r q / q)$ & r & شغل آزاد & \\
\hline & Ir $(ז N /)$ & $\operatorname{Ir}(\Delta T / T)$ & خانه دار & \\
\hline & $\Delta(1 N / \Delta)$ & $V(r \cdot / F)$ & بيكار & \\
\hline
\end{tabular}

ميانكَين I انحراف معيار

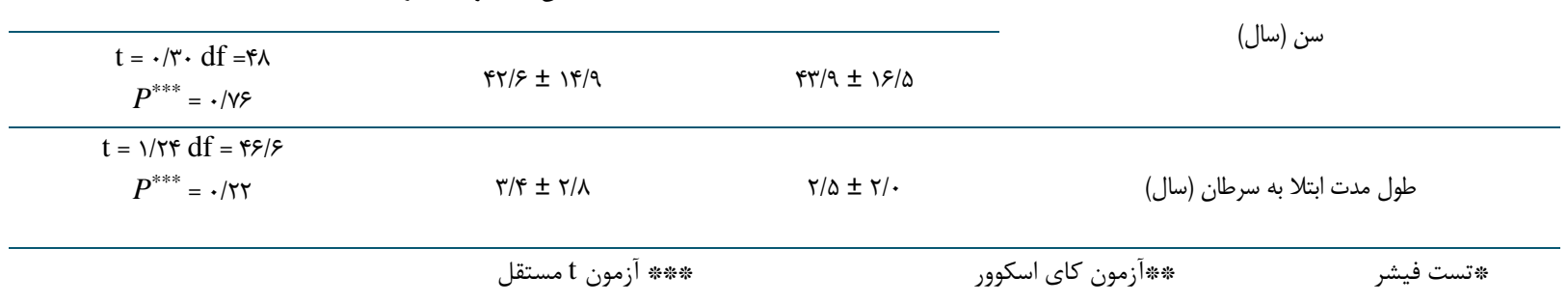

ارزيابى نهايى روى •له نفر (r نفر در گروه مداخله و TV نفر در گروه شاهد) از بيماران مبتلا به كانسر انجام شد (نمودار يك). بيشتر شركت كنند درصد) و متأهل (اس نفر يعنى بو بو درصد) با ميانگين سنى س/

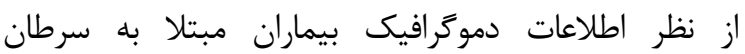
شركت كننده در مطالعه، تفاوت آمارى معنى دارى مشاهده نشد

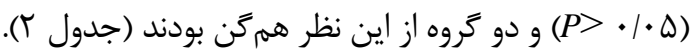

شد. در آزمونهاى انجامشده، سطح اطمينان ه9 درصد و

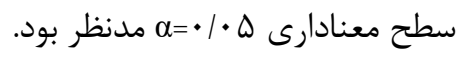

\section{بافتهها}

از له شركت كننده در مطالعه، \& نفر از ₹روه مداخله († نفر

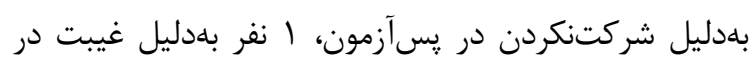

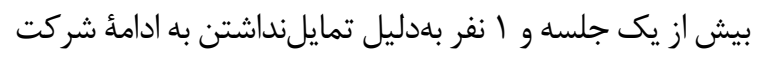
در مطالعه) در بررسى نهايى دادهها حذف شدند و بدينترتيب 
جدول با. مقايسئ اختلاف ميانكين شأن انسانى و ابعاد آن در بيماران مبتلا به سرطان قبل و پِ از مداخله بين كَروه كنترل و مداخله

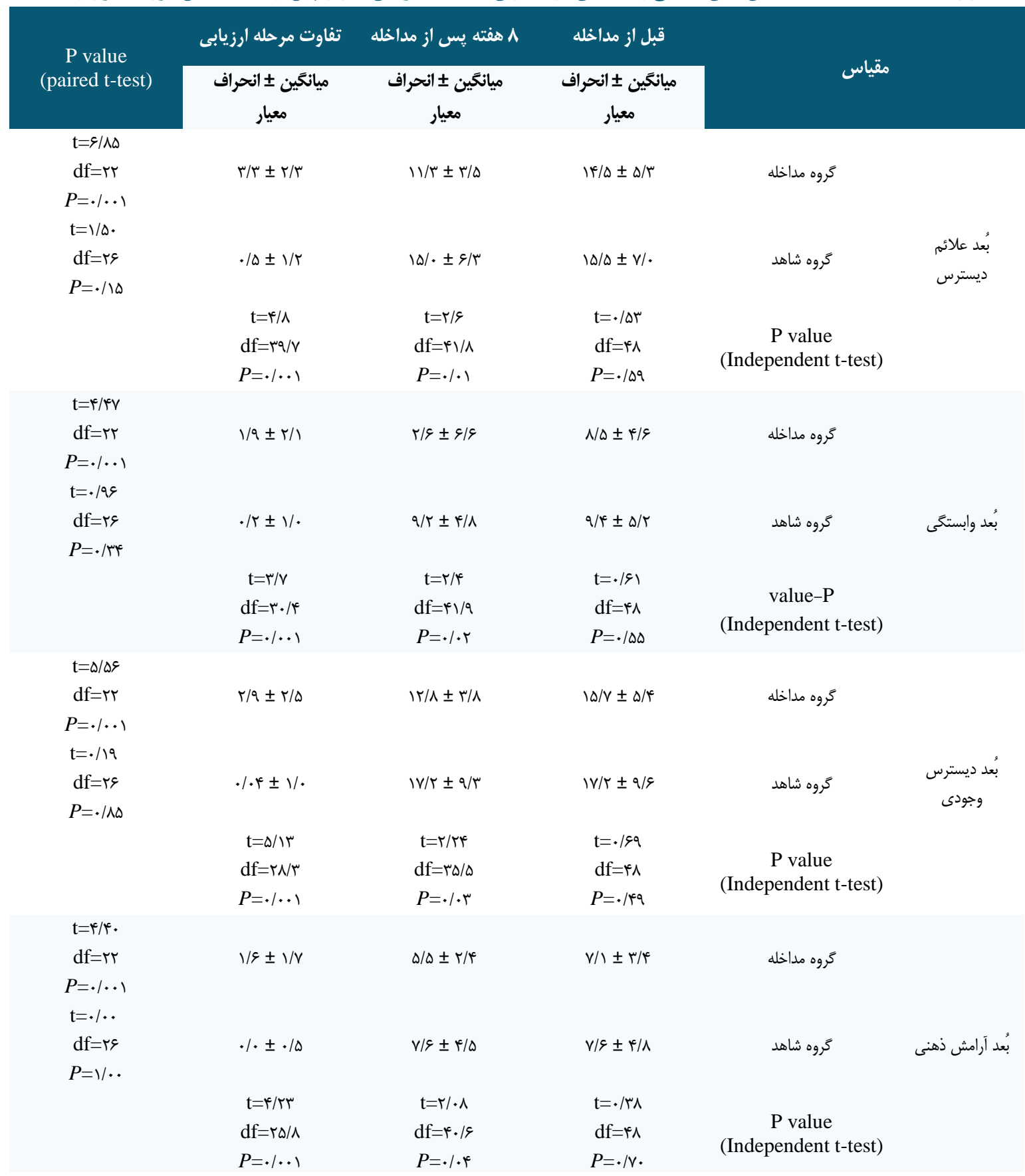

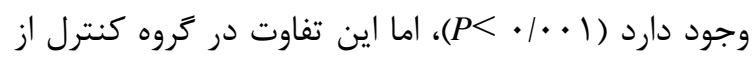

در مقايسٔ بين كروهى، نتايج آزمون t مستقل نشان داد

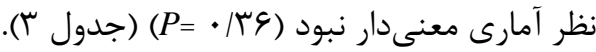
در مرحلة قبل از مداخله بين ميانكين نمرءٔ كل شأن انسانى

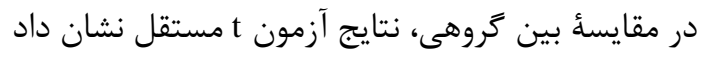

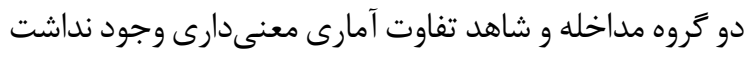

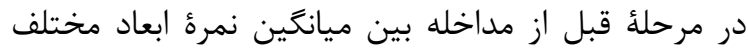

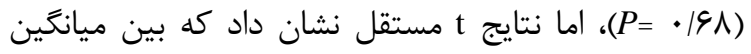
شأن انسانى (علائم ديسترس، وابستَى و...) دو گروه مداخله

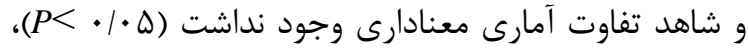
تغييرات نمرة كل شأن انسانى در دو كروه مداخله و شاهد

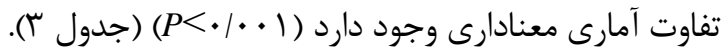
اما براساس نتايج t مستقل، بين ميانخين تغييرات نمرئ ابعاد در مقايسٔ درون كروهى، نتايج آزمون t زوج نشان داد

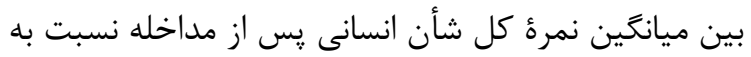

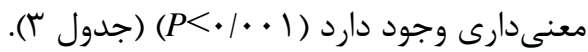

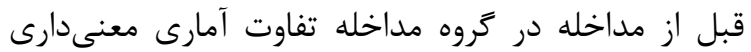




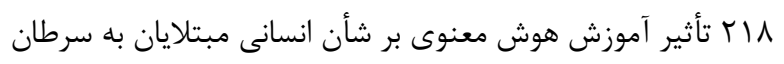

ادامه جدول س. مقايسهُ اختلاف ميانكين شأن انسانى و ابعاد آن در بيماران مبتلا به سرطان قبل و يس از مداخله بين گروه كنترل و مداخله

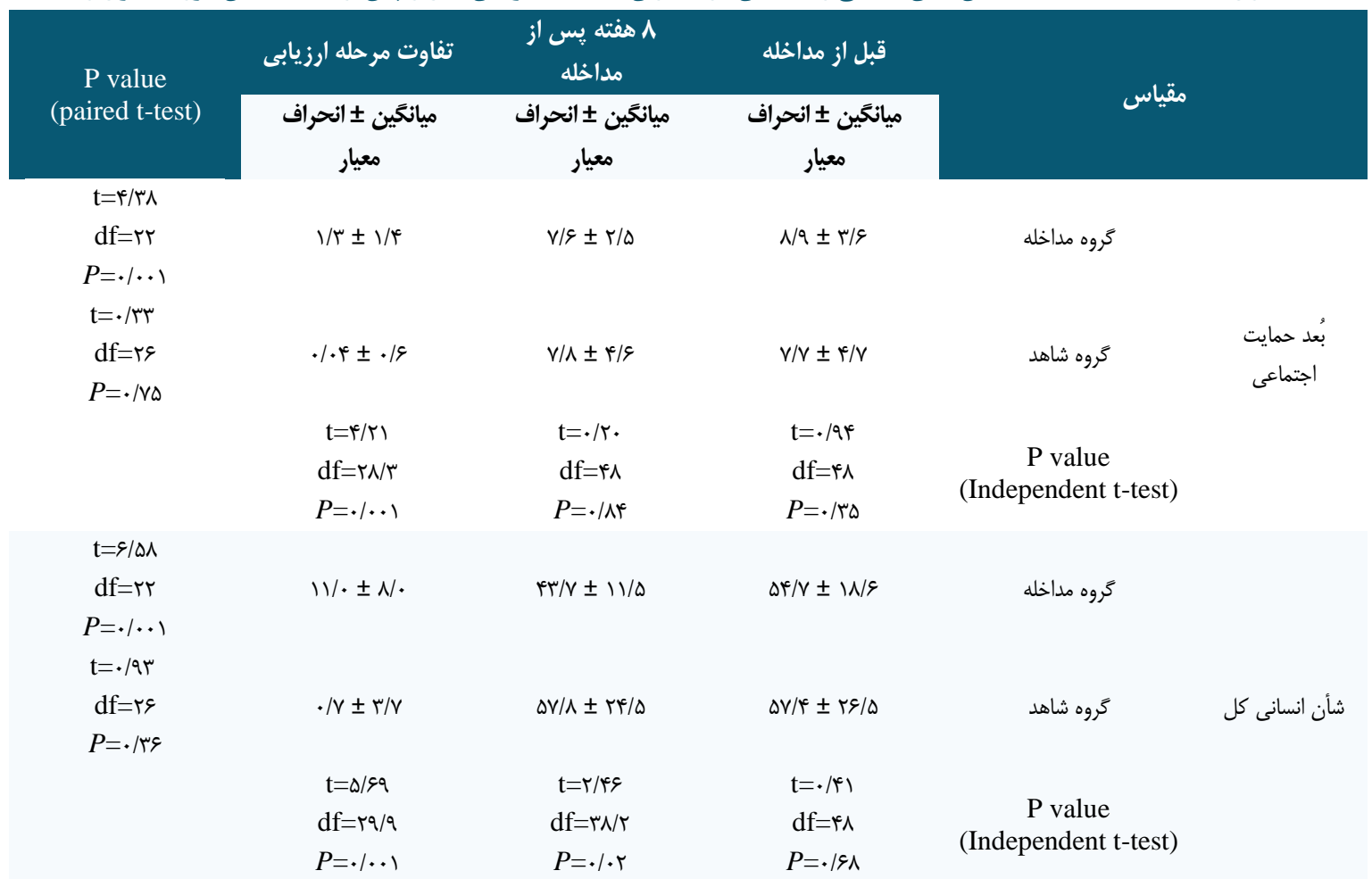

افراد مبتلا به سرطان به ميزان متوسطى در مقايسه با گروه

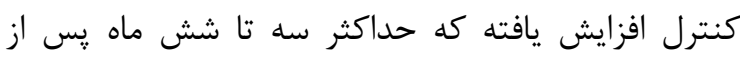

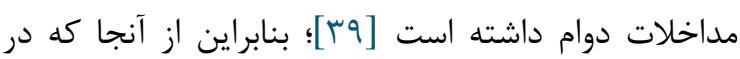
مطالعهُ حاضر يسآزمون دو ماه پِ إز مداخله اجرا شده

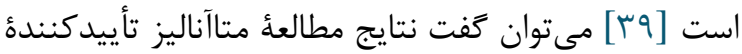
نتايج مطالعه حاضر است. ساير مطالعات در زمينهُ آموزش هوش معنوى بيانكر

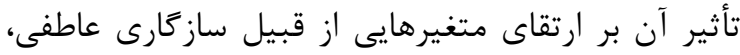

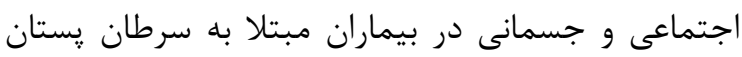

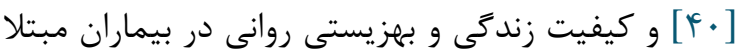

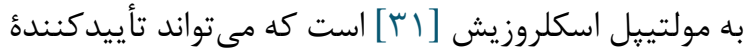
نتايج مطالعٔ حاضر باشد. همجنين مطالعاتى در داخل و

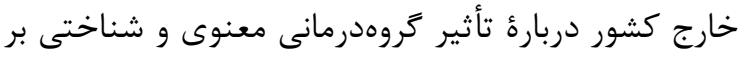
كاهش اضطراب مرك بيماران مبتلا به سرطان [TF] تأثير

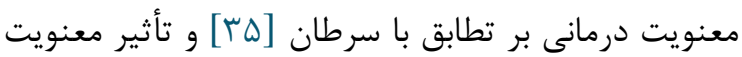

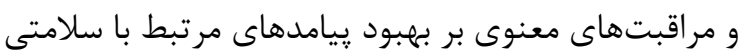

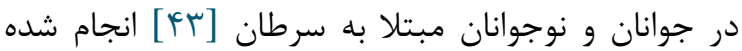
است كه با نتايج مطالعه حاضر همسوست. اكرجه نتايج

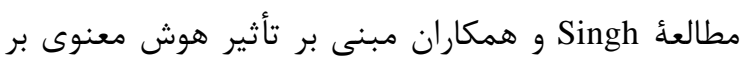

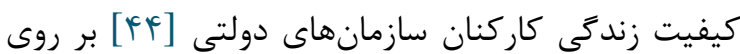

در مقايسه درون مروهى، نتايج آزمون t زوج نشان مىدهد ميان ميانكين نمرة ابعاد مختلف شأن انسانى (علائم

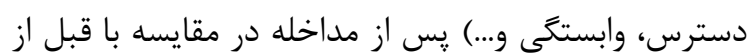
مداخله در كروه مداخله تفاوت آمارى معنادارى وجود داشت مدارت

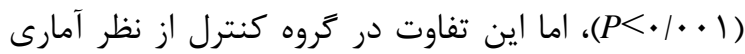

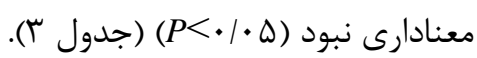

\section{بحث}

براساس نتايج مطالعهُ حاضر، بس از مداخلئ ميانكين نمرءٔ

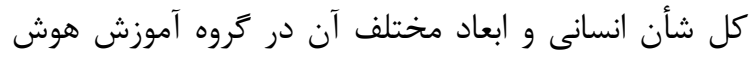
معنوى در مقايسه با كروه شاهد بهببود معنى دارى داشت همجنين مقايسٔ درون گروهى نشان مى دهد ميانگَين نمرءٔ كل

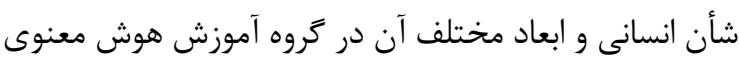

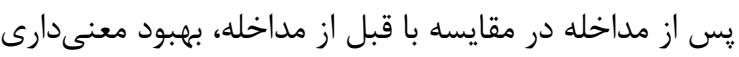
داشته، اما در كروه شاهد معنى دار نبوده است. براساس جستوجوهاى صورت كرفته، مطالعهاى كه

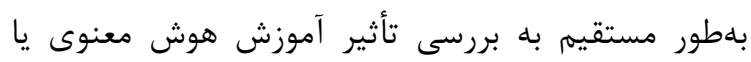

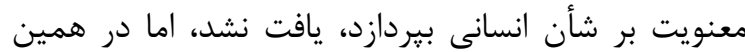

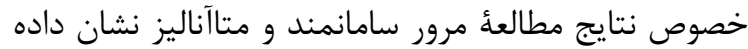

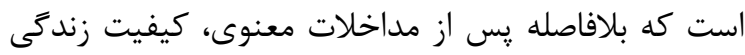




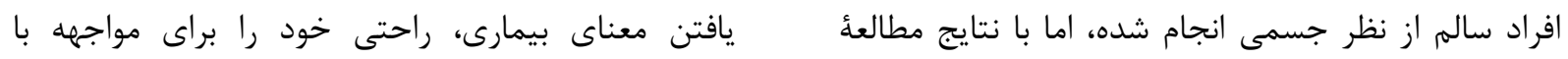

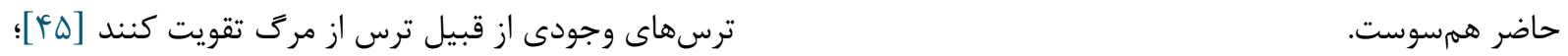

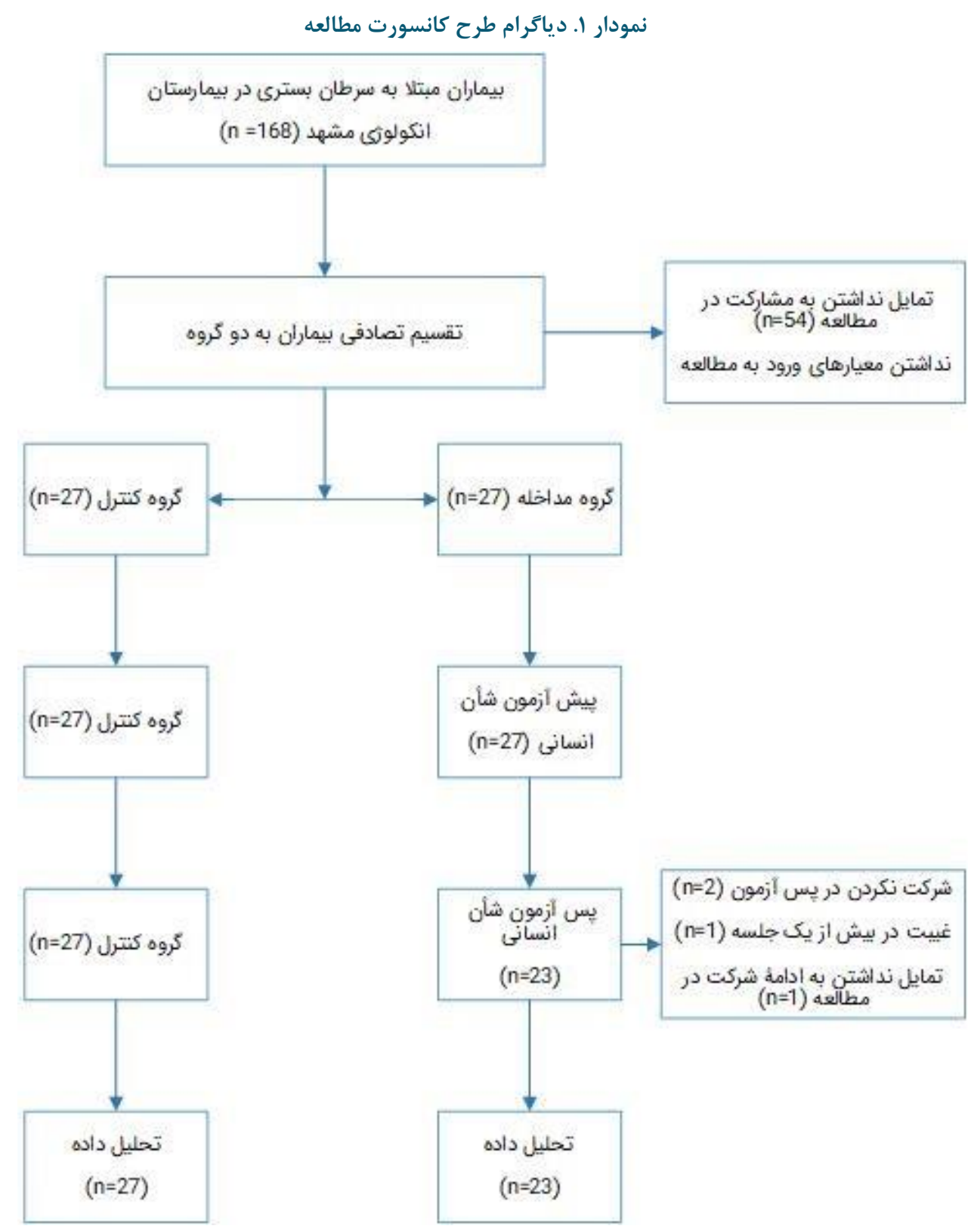

درحالى كه نيازهاى مراقبت معنوى در سياستهاى سيستم

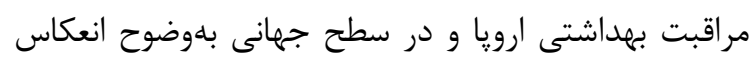

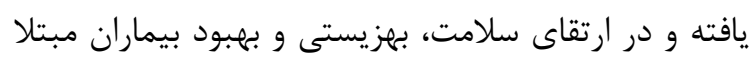

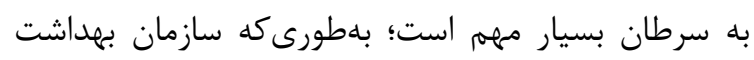

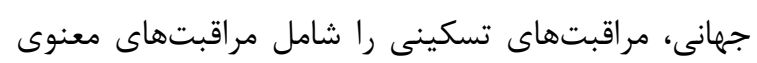

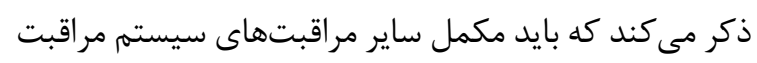

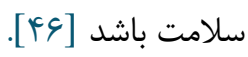

براساس جستوجوها، مطالعهاى كه نتايج آن متضاد با بال

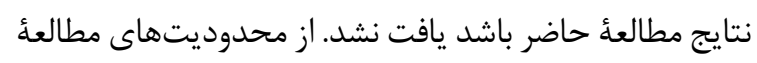

در تفسير نتايج مطالعهُ حاضر مىتوان كفت از آنجا كه

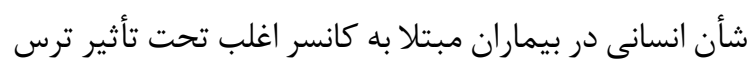

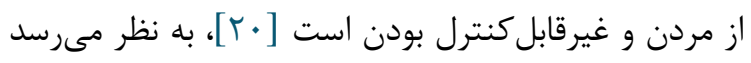

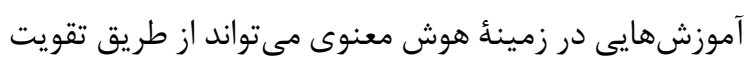

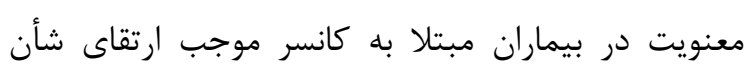

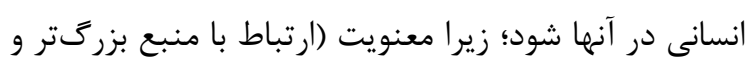

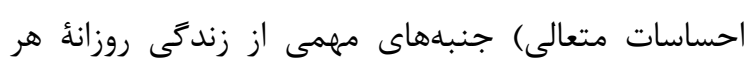

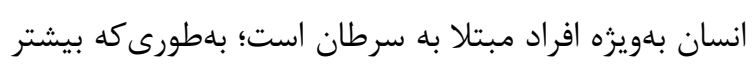

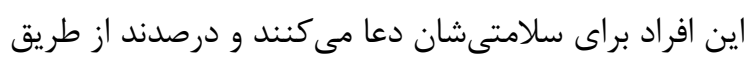


• Y r تأثير آموزش هوش معنوى بر شأن انسانى مبتلايان به سرطان

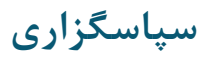

مقاله حاضر حاصل پِاياننامهُ دانشجويى مقطع

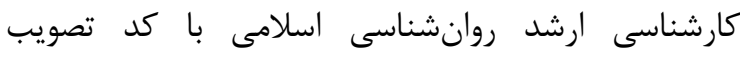

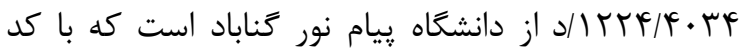
اخلاقى IR.MUMS.REC.1397.047 در كميتهٔ اخلاق

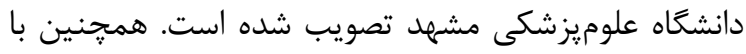
كد IRCT20180509039597N1 در مركز كارآزمايىهاى بالينى ايران ثبت و تأييد شده است. بدينوسيله بر خود لازم

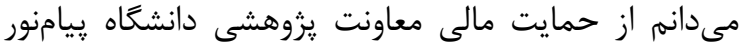

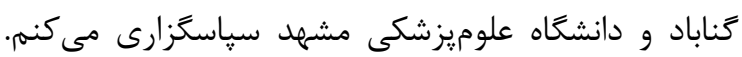
همجنين از همأ استادان دانشخاه بيامنور كناباد، مسئولان

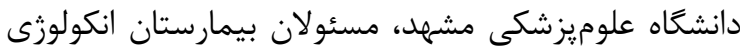

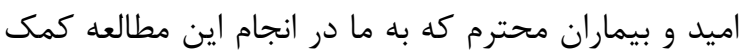
نمودند، تقدير و تشكر مىنماييهم.

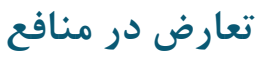

بين نويسندًان هيجَّونه تعارضى در منافع وجود ندارد

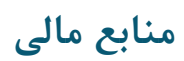

منابع مالى اين مطالعه توسط نويسندًان تامين شده است.

\section{References}

1. Hatamipour K, Rassouli M, Yaghmaie F, Zendedel K, Majd HA. Spiritual needs of cancer patients: A qualitative study. Indian journal of palliative care. 2015 Jan;21(1):61. [DOI:10.4103/0973-1075.150190] [PMID] [PMCID]

2. INCCCP. Iranian National Comprehensive Cancer Control

Program https://www.cdc.gov/cancer/ncccp/index.htm 2013 [Last accessed on 2017 Aug 31 [

3. Organization WH. fact sheet on cancer http://www.who.int/mediacentre/factsheets/fs297/en/. 2015 [

4. Rassouli M, Sajjadi M. Cancer care in countries in transition: The Islamic Republic of Iran. InCancer Care in Countries and Societies in Transition 2016 (pp. 317-336). Springer, Cham. [DOI:10.1007/978-3-31922912-6_20]

5. Maule M, Merletti F. Cancer transition and priorities for cancer control. The lancet oncology. 2012 Aug 1;13(8):745-6. [DOI:10.1016/S1470-2045(12)702681]

$$
\text { دورة TV شمارة F F - مهر و آبان }
$$

حاضر اجراى اين مطالعه بر بيماران مبتلا به سرطان بسترى

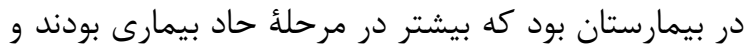

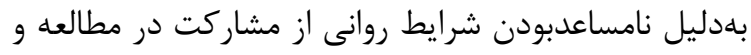
تكميل ييش آزمون امتناع مى كردند. از سويى، محل ابتلا به به سرطان مىتوانست بر وضعيت بيمار از نظر روانى و جسمانى

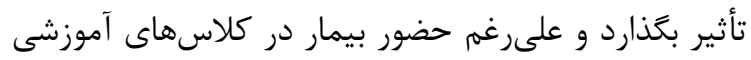

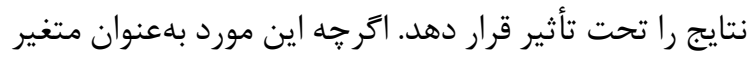

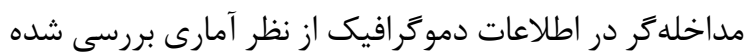
بود؛ بنابراين بيشنهاد مى شود در مطالعات آينده اين مطالعه

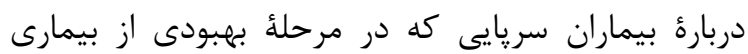

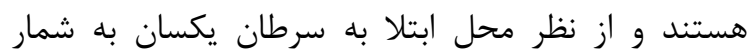

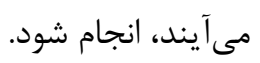

$$
\text { نتيجه }
$$

براساس نتايج مطالعُ حاضر، آموزش هوش معنوى مى مي

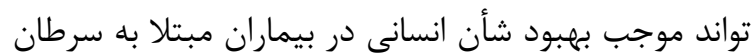
شود؛ از اينرو توصيه مىشود در بيمارستانها علاوه بر بران

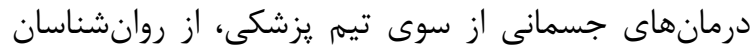

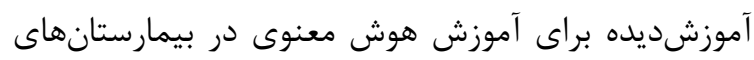

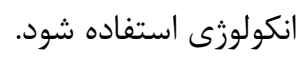

6. Bahrami M. Meanings and aspects of quality of life for cancer patients: A descriptive exploratory qualitative study. Contemporary nurse. 2011 Aug 1;39(1):75-84. [DOI:10.5172/conu.2011.39.1.75] [PMID]

7. Zhang X, Xiao H, Chen Y. Effects of life review on mental health and well-being among cancer patients: A systematic review. International Journal of Nursing Studies. $\quad 2017 \quad$ Sep $\quad 1 ; 74: 138-48$ [DOI:10.1016/j.ijnurstu.2017.06.012] [PMID]

8. Tuncer G, Yucel SC. Comfort and anxiety levels of women with early stage breast cancer who receive radiotherapy. Asian Pac J Cancer Prev. 2014 Jan 1;15(5):2109-14.

[DOI:10.7314/APJCP.2014.15.5.2109] [PMID]

9. Lee SJ, Park JH, Park BY, Kim SY, Lee IH, Kim JH, Koh DH, Kim CH, Sohn MS. Depression and suicide ideas of cancer patients and influencing factors in South Korea. Asian Pac J Cancer Prev. 2014 Jan 1;15(7):2945-50 [DOI:10.7314/APJCP.2014.15.7.2945] [PMID]

10. Pearson EJ, Morris ME, McKinstry CE. Cancerrelated fatigue: a survey of health practitioner knowledge and practice. Supportive Care in Cancer. 2015 Dec 1;23(12):3521-9. [DOI:10.1007/s00520015-2723-8] [PMID]

$$
\text { مجله مراقبت يرستارى و مامايى ابنسينا }
$$


11. Blinderman CD, Cherny NI. Existential issues do not necessarily result in existential suffering: lessons from cancer patients in Israel. Palliative medicine. 2005 Jul;19(5):371-80.

[DOI:10.1191/0269216305pm1038oa] [PMID]

12. Boston P, Bruce A, Schreiber R. Existential suffering in the palliative care setting: an integrated literature review. Journal of pain and symptom management. 2011 Mar 1;41(3):604-18 [DOI:10.1016/j.jpainsymman.2010.05.010] [PMID]

13. Afrooz R, Rahmani A, Zamanzadeh V, Abdullahzadeh F, Azadi A, Faghany S, Pirzadeh A. The nature of hope among Iranian cancer patients. Asian Pac J Cancer Prev. $2014 \quad$ Jan 1;15(21):9307-12 [DOI:10.7314/APJCP.2014.15.21.9307] [PMID]

14. Chochinov HM. Dignity and the essence of medicine: the A, B, C, and D of dignity conserving care. Bmj. 2007 Jul 26;335(7612):184-7. [DOI:10.1136/bmj.39244.650926.47] [PMID] [PMCID]

15. Rodríguez-Prat A, Monforte-Royo C, Porta-Sales J, Escribano X, Balaguer A. Patient perspectives of dignity, autonomy and control at the end of life: systematic review and meta-ethnography. PloS one. 2016 Mar 24;11(3):e0151435. [DOI:10.1371/journal.pone.0151435] [PMID] [PMCID]

16. Philipp R, Mehnert A, Lehmann C, Oechsle K, Bokemeyer C, Krüll A, Vehling S. Detrimental social interactions predict loss of dignity among patients with cancer. Supportive Care in Cancer. 2016 Jun 1;24(6):2751-8. [DOI:10.1007/s00520-016-3090-9] [PMID]

17. Parandeh A, Khaghanizade M, Mohammadi E, Mokhtari-Nouri J. Nurses' human dignity in education and practice: An integrated literature review. Iranian journal of nursing and midwifery research. 2016 Jan;21(1):1. [DOI:10.4103/1735-9066.174750] [PMID] [PMCID]

18. Omathuna DP. The place of dignity in everyday ethics. J Christ Nurs . $2011 \quad ; 28(1): 12-8$ https://doi.org/10.1097/CNJ.0b013e3181fe7606 [DOI:10.1097/CNJ.0b013e3181fe7606 .] [PMID]

19. Whitehead J, Wheeler H. Patients' experiences of privacy and dignity. Part 1: a literature review. British Journal of Nursing. 2008 Mar 27;17(6):381-5. [DOI:10.12968/bjon.2008.17.6.28904] [PMID]

20. Chochinov HM, Hassard T, McClement S, Hack T, Kristjanson LJ, Harlos M, Sinclair S, Murray A. The patient dignity inventory: a novel way of measuring dignity-related distress in palliative care. Journal of pain and symptom management. 2008 Dec 1;36(6):559-71.

[DOI:10.1016/i.jpainsymman.2007.12.018] [PMID]

21. Vehling S, Mehnert A. Symptom burden, loss of dignity, and demoralization in patients with cancer: a mediation model. Psycho-Oncology. 2014 Mar;23(3):283-90. [DOI:10.1002/pon.3417] [PMID]

22. LeBaron VT, Cooke A, Resmini J, Garinther A, Chow V, Quiñones R, Noveroske S, Baccari A, Smith PT,
Peteet J, Balboni TA. Clergy views on a good versus a poor death: ministry to the terminally ill. Journal of palliative medicine. 2015 Dec 1;18(12):1000-7. [DOI:10.1089/jpm.2015.0176] [PMID] [PMCID]

23. Borhani F, Abbaszadeh A, Rabori RM. New vision for the dignity: understanding the meaning of patient dignity in Iran. Br J Med Med Res. 2015 Feb 1;9(2):11. [DOI:10.9734/BJMMR/2015/18886]

24. Thuné-Boyle IC, Stygall J, Keshtgar MR, Davidson TI, Newman SP. Religious/spiritual coping resources and their relationship with adjustment in patients newly diagnosed with breast cancer in the UK. PsychoOncology. $2013 \quad$ Mar;22(3):646-58. [DOI:10.1002/pon.3048] [PMID]

25. Pargament KI, Koenig HG, Perez LM. The many methods of religious coping: Development and initial validation of the RCOPE. Journal of clinical psychology. $2000 \quad$ Apr;56(4):519-43. https://doi.org/10.1002/(SICI) 10974679(200004)56:4<519::AID-JCLP6>3.0.CO;2-1 [DOI:10.1002/(SICI) 1097 4679(200004)56:43.0.CO;2-1]

26. Pargament KI, Smith BW, Koenig HG, Perez L. Patterns of positive and negative religious coping with major life stressors. Journal for the scientific study of religion. 1998 Dec 1:710-24. [DOI:10.2307/1388152]

27. Marshall IN. SQ: spiritual intelligence: the ultimate intelligence. Bloomsbury; 2000.

28. George M. How intelligent are you... really? From IQ to EQ to SQ, with a little intuition along the way. Training \& Management Development Methods. 2006 Aug 10;20(4):425.36.

29. Vaughan F. What is spiritual intelligence? Journal of Humanistic Psychology. 2003;42(2):16-33. [DOI: $10.1177 / 0022167802422003$ ]

30. Bowell RA. The seven steps of spiritual intelligence: The practical pursuit of purpose, success, and happiness. Nicholas Brealey Publishing; 2004.

31. King DB. Rethinking claims of spiritual intelligence: A definition, model, an measure. Canada Trent University (Canada); 2008.

32. Nasel DD. Spiritual orientation in relation to spiritual intelligence: a consideration of traditional Christianity and new age/individualistic Spirituality The University of South Australia; 2004.

33. Elkins M, Cavendish R. Developing a plan for pediatric spiritual care. Holistic Nursing Practice. 2004 Jul 1;18(4):179-84. [DOI:10.1097/00004650200407000-00002] [PMID]

34. Moazedyan P, Bagheri M. The spiritual intelligence training to family, affective, social and Physical adjustments in breast cancer patients Biannual Journal of Applied. 2016;6(1):89-101.

35. Movafagh A, Heidari MH, Abdoljabbari M, Mansouri N, Taghavi A, Karamatinia A, Mehrvar N, Hashemi M, Ghazi M. Spiritual therapy in coping with cancer as a complementary medical preventive practice. Journal of cancer prevention. 2017 Jun;22(2):82. [DOI:10.15430/JCP.2017.22.2.82] [PMID] [PMCID]

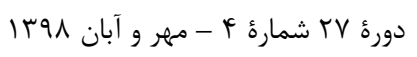

$$
\text { مجله مراقبت برستارى و مامايى ابنسينا }
$$


36. Salajegheh $\mathrm{S}$, Raghibi $\mathrm{M}$. The effect of combined therapy of spiritual-cognitive group therapy on death anxiety in patients with cancer. SSU_Journals. 2014 Jun 15;22(2):1130-9.

37. Chochinov HM, Hassard T, McClement S, Hack T, Kristjanson LJ, Harlos M, Sinclair S, Murray A. The patient dignity inventory: a novel way of measuring dignity-related distress in palliative care. Journal of pain and symptom management. 2008 Dec 1;36(6):559-71.

[DOI:10.1016/j.jpainsymman.2007.12.018] [PMID]

38. Vaghee S, Mazlom S, Davoudi N, Modares Gharav M. The effect of dignity therapy on human dignity in patients with chronic renal failure undergoing hemodialysis. Evidence Based Care. 2013 Jul 1;3(2):63-72.

39. Kruizinga R, Hartog ID, Jacobs M, Daams JG, Scherer-Rath M, Schilderman JB, Sprangers MA, Van Laarhoven HW. The effect of spiritual interventions addressing existential themes using a narrative approach on quality of life of cancer patients: a systematic review and meta-analysis. PsychoOncology. $2016 \quad$ Mar;25(3):253-65. [DOI:10.1002/pon.3910] [PMID]

40. Moazedyan P, Bagheri $\mathrm{M}$. The spiritual intelligence training to family, affective, social and Physical adjustments in breast cancer patients. Biannual Journal of Applied Counseling. 2016;6(1):89-101.

41. Zamani SN, Hajializadeh K. Studying effect of instructing spiritual intelligence on life quality and psychological well-being in patients with multiple sclerosis. South Journal of Educational Psychology and Counseling. 2015;2(1):28-36.

42. Salajegheh S, Raghibi M. The effect of combined therapy of spiritual-cognitive group therapy on death anxiety in patients with cancer. SSU_Journals. 2014 Jun 15;22(2):1130-9.

43. Taylor EJ, Petersen C, Oyedele O, Haase J. Spirituality and Spiritual Care of Adolescents and Young Adults with Cancer. Seminars in Oncology Nursing. 2015;31(3):227-41.

[DOI:10.1016/j.soncn.2015.06.002] [PMID]

44. Singh MP, Sinha J. Impact of spiritual intelligence on quality of life. International Journal of Scientific and Research Publications. 2013 May;3(5):1-5.

45. Jim HS, Pustejovsky JE, Park CL, Danhauer SC, Sherman AC, Fitchett G, Merluzzi TV, Munoz AR, George L, Snyder MA, Salsman JM. Religion, spirituality, and physical health in cancer patients: A meta-analysis. Cancer. 2015 Nov 1;121(21):3760-8. [DOI:10.1002/cncr.29353] [PMID] [PMCID]

46. van Meurs J, Smeets W, Vissers KC, Groot M, Engels Y. Nurses exploring the spirituality of their patients with cancer: Participant observation on a medical oncology ward. Cancer nursing. 2018 Jul;41(4):E39. [DOI: 10.1097/NCC.0000000000000526] [PMID] [PMCID] 